\title{
Dynamical magnetic behavior of anisotropic spinel-structured ferrite for $\mathrm{GHz}$ technologies
}

\author{
Yukiko Yasukawa ${ }^{1 凶}$, Kouhei Nozawa², Taneli Tiittanen ${ }^{3}$, Maarit Karppinen $^{3}$, Johan Lindén ${ }^{4}$,
} Sagar E. Shirsath ${ }^{5}$ \& Shin Yabukami ${ }^{2}$

We have fabricated a high quality magnetic $\mathrm{Ni}_{0.5} \mathrm{Zn}_{0.5} \mathrm{Fe}_{2} \mathrm{O}_{4}$ ferrite powder/polymer composite sheet consisting of common and environmentally friendly elements only. The sheet was then tested for its dynamic permeability by irradiating with electromagnetic waves with frequencies up to $50 \mathrm{GHz}$. Two different originally developed methods were used for the high-frequency permeability measurements, a short-circuited microstrip line method and a microstrip line-probe method. It is challenging to measure the dynamic permeability of magnetic thin films/sheets beyond $10 \mathrm{GHz}$ because of the low response signal from these materials. However, the two methods produced essentially equivalent results. In the frequency dependent permeability profile, the maximum position of the profile, $\mu_{\text {maxı }}^{\prime \prime}$ shifted towards higher frequencies upon increasing an applied (strong) static external magnetic field, $H_{d c}$. A linear relationship between $\mu_{\max }^{\prime \prime}$ and $H_{d c}$ for the entire range of $H_{d c}$ was observed even at small $H_{d c}$. In general, the spinel-structured Ni-based ferrites exhibit low magnetic anisotropy, but the present sample showed a uniaxial-anisotropic behavior in the parallel direction of the sheet. Our $\mathrm{Ni}_{0.5} \mathrm{Zn}_{0.5} \mathrm{Fe}_{2} \mathrm{O}_{4}$ powder/polymer composite sheet thus exhibits high performance at $\mathrm{GHz}$ frequencies, and should be applicable e.g. as an anisotropic electromagnetic wave-interference material.

Current telecommunication systems and electronic devices with super-high functionalities are operated by GHzfrequency electromagnetic waves. Consequently, magnetic materials working in the high $\mathrm{GHz}$-frequency region are indispensable for e.g. sensing and spintronic torque-oscillation devices, electromagnetic wave absorbers, and magnetic sheets for radio-frequency identification (RFID). For the practical use of these magnetic materials, dynamic permeability behaviors under the irradiation of high-frequency electromagnetic waves is a key issue, because permeability determines the applicable frequency bands of magnetic-based devices. For instance, the resonance frequency $\left(f_{r}\right)$ should be in the $\mathrm{MHz}$ region for a magnetic-based electromagnetic wave shield, which is applied to wireless-power transmission circuits ${ }^{1}$. On the other hand, magnetic materials exhibiting $f_{r}$ values in the $\mathrm{GHz}$ region can be used as electromagnetic wave absorbers inside mobile phones.

Typically, the dynamic permeability of the GHz region is evaluated based on reflection or transmission methods. In these methods, microstrip line (MSL), coaxial and coplanar waveguides are commonly used. The measurement results obtained from experiments are usually analyzed by the lumped-element approximation ${ }^{2,3}$, or the distributed-element approximation ${ }^{4,5}$. Moreover, some groups measure the high-frequency permeability using commercialized-product devices, while others develop new devices aiming at more accurate measurements/analyses for the higher frequencies of the " $5 \mathrm{G}$ era". Thus, various combinations of experimental devices, measurement techniques, and analysis methods have been employed to evaluate the dynamic permeability, such that the measurement/analysis procedures are often strongly specific to the different research groups ${ }^{6-11}$.

Ferrites are promising materials for high-frequency devices ${ }^{12}$ because of their ferromagnetic resonance (FMR) in the $\mathrm{MHz}$ - to $\mathrm{GHz}$-frequency region. High resistivity but low conduction losses in the high-frequency region is another prominent advantage of ferrites. Magnetoplumbite-structured ferrites with a chemical formula of $A \mathrm{Fe}_{12} \mathrm{O}_{19}\left(A=\right.$ alkali or alkaline-earth metal) have been widely studied, as $f_{r}$ is expected to reach as high as $\sim 50 \mathrm{GHz}$ for these materials ${ }^{8,13-15}$. For example, in a Sm-doped high purity single-crystal $\mathrm{SrFe}_{12} \mathrm{O}_{19} f_{r}$ was found to be $53 \mathrm{GHz}^{16}$. However, keeping an eye on the recent high-frequency technologies, the electromagnetic

\footnotetext{
${ }^{1}$ Department of Electrical and Electronic Engineering, Faculty of Engineering, Chiba Institute of Technology, 2-17-1 Tsudanuma, Narashino, Chiba 275-0016, Japan. ${ }^{2}$ Graduate School of Engineering, Tohoku University, Building No. 2, 6-6-05 Aoba Aza Aramaki, Aoba, Sendai, Miyagi 980-8579, Japan. ${ }^{3}$ Department of Chemistry and Materials Science, Aalto University, 00076 Espoo, Finland. "Physics/Faculty of Science and Engineering, Åbo Akademi, Porthansg. 3, 20500 Turku, Finland. ${ }^{5}$ School of Materials Science and Engineering, University of New South Wales, Sydney, NSW 2052, Australia. ${ }^{\boxplus}$ email: yukiko.yasukawa@p.chibakoudai.jp
} 
wave interference (EMI) may become a serious problem. In this regard, the magnetoplumbite-structured $A \mathrm{Fe}_{12} \mathrm{O}_{19}$ ferrites ${ }^{17}$, spinel-structured $\mathrm{Ni}_{1-\mathrm{x}} \mathrm{Zn}_{\mathrm{x}} \mathrm{Fe}_{2} \mathrm{O}_{4}$ ferrites, and soft magnetic alloy materials mixed with polymers ${ }^{18}$ are expected to be attractive materials, especially in the field of EMI at $\mathrm{GHz}$ bands.

In this study, we evaluate the dynamic permeability behavior of ferrites under the irradiation of an electromagnetic wave of $\mathrm{GHz}$ frequency through two different originally developed measurement techniques, (i) shortcircuited MSL ${ }^{10,15,19}$, and (ii) MSL-probe ${ }^{11,20}$ methods. Our aim is to provide a comprehensive understanding of the dynamical magnetic behaviors of ferrites in the $\mathrm{GHz}$ region. For both measurement methods, the same sample, i.e., $\mathrm{Ni}_{0.5} \mathrm{Zn}_{0.5} \mathrm{Fe}_{2} \mathrm{O}_{4}$ powder/polymer composite sheet from the same sample batch, was used. We used polyvinyl alcohol (PVA) as a polymer source. It should be noted that the spinel-structured $\mathrm{Ni}_{0.5} \mathrm{Zn}_{0.5} \mathrm{Fe}_{2} \mathrm{O}_{4}$ is widely commercialized because of its simpler crystal structure compared to the $A \mathrm{Fe}_{12} \mathrm{O}_{19}$ ferrites with the magnetoplumbite structure. Therefore, it is an optimal material for the present study.

\section{Results and discussion}

Verification of the quality of the $\mathrm{Ni}_{0.5} \mathrm{Zn}_{0.5} \mathrm{Fe}_{2} \mathrm{O}_{4}$ powder. The high sample quality was an essential requirement for the present study. Hence we started the study by confirming the phase purity and the fundamental structural and physical properties of the synthesized $\mathrm{Ni}_{0.5} \mathrm{Zn}_{0.5} \mathrm{Fe}_{2} \mathrm{O}_{4}$ ceramic powder. First of all, the XRD pattern shown in Fig. la confirms the cubic spinel structure (lattice parameter determined at $8.398 \AA$ in excellent agreement with the value of $8.383 \AA$ given in the JCPDS card) for the sample without any impurity phase peaks. Moreover, the half-width-at-half-maximum (HWHM) value of $0.05^{\circ}$ for the strongest (311) peak indicates excellent crystallinity.

Further evidence of the high sample quality of our $\mathrm{Ni}_{0.5} \mathrm{Zn}_{0.5} \mathrm{Fe}_{2} \mathrm{O}_{4}$ ceramic powder was obtained from the microstructural study. From the FE-SEM image (Fig. 1b) it could be seen that the powder consists of crystallites larger than $100 \mu \mathrm{m}$. The local-crystal structure observation by high-angle annular dark-field (HAADF) with an incident-electron beam from [011] revealed well-ordered arrangements of atoms (Fig. 1c). Moreover, we confirmed the Ni, Zn, Fe, and O signals from the TEM-EDS analysis. Finally, Fig. 1d displays an enlarged image of Fig. 1c, and its inset shows the simulated atomic positions of the spinel-structured ferrite. For this simulation, the atomic positions were taken from a literature ${ }^{21}$. In the simulated image, oxygen atoms are drawn in red, $A$-site cations in tetrahedra in green, and $B$-site cations in octahedra in blue. There are two distinct $B$-site cations in the simulated image, marked by blue circles and a blue arrow. It is noteworthy to point out that these two types of $B$-site cations can be recognized in Fig. $1 \mathrm{~d}$. The simulated atomic positions and the atomic configurations are consistent with the interpretation of Fig. 1d. In Fig. 1e we display a simulated diffraction pattern for a spinelstructured ferrite with a thickness of $4.2 \mathrm{~nm}$. By comparing the observed (Fig. 1d) and simulated (Fig. 1e) images, the high/low-color contrasts of both the images are consistent with the following interpretation: $B$-site cations marked by blue circles exhibit higher contrast, while the position exhibiting indistinct contrast is due to atoms indicated by a blue arrow. Furthermore, the $A$-site cation indicated by a green arrow exhibits low contrast in Fig. 1d, which agrees with the simulated result (Fig. 1e).

We also confirmed the magnetic property of our $\mathrm{Ni}_{0.5} \mathrm{Zn}_{0.5} \mathrm{Fe}_{2} \mathrm{O}_{4}$ ceramic powder; from Fig. $1 \mathrm{f}$ it shows the typical soft magnetic behavior with a low coercivity $\left(H_{c}\right)$ value of $13 \mathrm{Oe}$, and saturation-magnetization $\left(M_{s}\right)$ of $78 \mathrm{emu} / \mathrm{g}$, in agreement with the values reported by other groups ${ }^{22,23}$. Mössbauer spectroscopy enabled us to simultaneously determine the oxidation state, chemical surrounding and magnetic structure; we performed Mössbauer measurements on our $\mathrm{Ni}_{0.5} \mathrm{Zn}_{0.5} \mathrm{Fe}_{2} \mathrm{O}_{4}$ ceramic powder at room temperature without applying an external magnetic field. The spectrum consisted of several magnetically broadened components and one paramagnetic component. The paramagnetic component was assigned to a Fe atom surrounded only by $\mathrm{Zn}$ atoms, thereby the local magnetic coupling of this Fe species was broken. The isomer shift values indicated that all the Fe atoms in the $\mathrm{Ni}_{0.5} \mathrm{Zn}_{0.5} \mathrm{Fe}_{2} \mathrm{O}_{4}$ ceramic powder are trivalent $\left(\mathrm{Fe}^{3+}\right)$ in a high-spin state without any traces of divalent $\mathrm{Fe}$ $\left(\mathrm{Fe}^{2+}\right)$. This confirms that the present sample is fully oxygenated, indicating that a high resistivity is expected.

Static physical behavior of the $\mathrm{Ni}_{0.5} \mathrm{Zn}_{0.5} \mathrm{Fe}_{2} \mathrm{O}_{4}$ powder/polymer composite sheet. Prior to the preparation of sheet-shaped $\mathrm{Ni}_{0.5} \mathrm{Zn}_{0.5} \mathrm{Fe}_{2} \mathrm{O}_{4}$ powder/polymer composites, the $\mathrm{Ni}_{0.5} \mathrm{Zn}_{0.5} \mathrm{Fe}_{2} \mathrm{O}_{4}$ ceramic powder was crushed using a grinding machine to achieve homogeneous-sized particles leading to homogeneous physical properties. Afterward, the powder was classified based on the sizes of particles by the use of 180, 120, and $90 \mu \mathrm{m}$ sieves, successively. The distribution of the particle size of the ceramic $\mathrm{Ni}_{0.5} \mathrm{Zn}_{0.5} \mathrm{Fe}_{2} \mathrm{O}_{4}$ powder after the classification is shown in Fig. 2a. The largest number of particles occurs at approximately $50 \mu \mathrm{m}$, while the median value of the particle size is $25 \mu \mathrm{m}$. By using homogeneous-sized $\mathrm{Ni}_{0.5} \mathrm{Zn}_{0.5} \mathrm{Fe}_{2} \mathrm{O}_{4}$ ceramic powder, we prepared a sheet-shaped $\mathrm{Ni}_{0.5} \mathrm{Zn}_{0.5} \mathrm{Fe}_{2} \mathrm{O}_{4}$ powder/polymer composite as described in the Method section. The appearance of the prepared sheet is shown in Fig. 2b. The average thickness of the sheet is $225 \mu \mathrm{m}$. The FE-SEM image shown in Fig. $2 \mathrm{c}$ reveals that $\mathrm{Ni}_{0.5} \mathrm{Zn}_{0.5} \mathrm{Fe}_{2} \mathrm{O}_{4}$ particles with various shapes are embedded in the polymer matrix. Also seen is that the sheet exhibits some surface roughness. The distribution of constituent elements of the sheet analyzed by EDS is in Fig. 2d; in the EDS mapping red corresponds to Fe, whereas C is denoted as green. It is inferred that the location of Fe corresponds to the existence of ferrite particles. In contrast, the signal from $\mathrm{C}$ shows the distribution of the polymer. In the present sheet, $\mathrm{C}$ is selectively detected at the boundary of the $\mathrm{Ni}_{0.5} \mathrm{Zn}_{0.5} \mathrm{Fe}_{2} \mathrm{O}_{4}$ particles, thereby each $\mathrm{Ni}_{0.5} \mathrm{Zn}_{0.5} \mathrm{Fe}_{2} \mathrm{O}_{4}$ particle is isolated by the polymer matrix. The surface resistivity of the $\mathrm{Ni}_{0.5} \mathrm{Zn}_{0.5} \mathrm{Fe}_{2} \mathrm{O}_{4}$-powder/polymer composite sheet measured under an application voltage of $10 \mathrm{~V}$ at room temperature is $1.09 \times 10^{9} \Omega$, which is sufficiently high. Thus, the influence of eddy currents in the sheet can be ruled out when high frequency electromagnetic wave is irradiated on the sample. This is a great advantage for materials applied in high-frequency technologies.

The magnetic properties of the $\mathrm{Ni}_{0.5} \mathrm{Zn}_{0.5} \mathrm{Fe}_{2} \mathrm{O}_{4}$-powder/polymer composite sheet were measured by applying an external magnetic field parallel with $(/ /)$ and perpendicular to $(\perp)$ the surface of the sheet (Fig. 2e). Note 

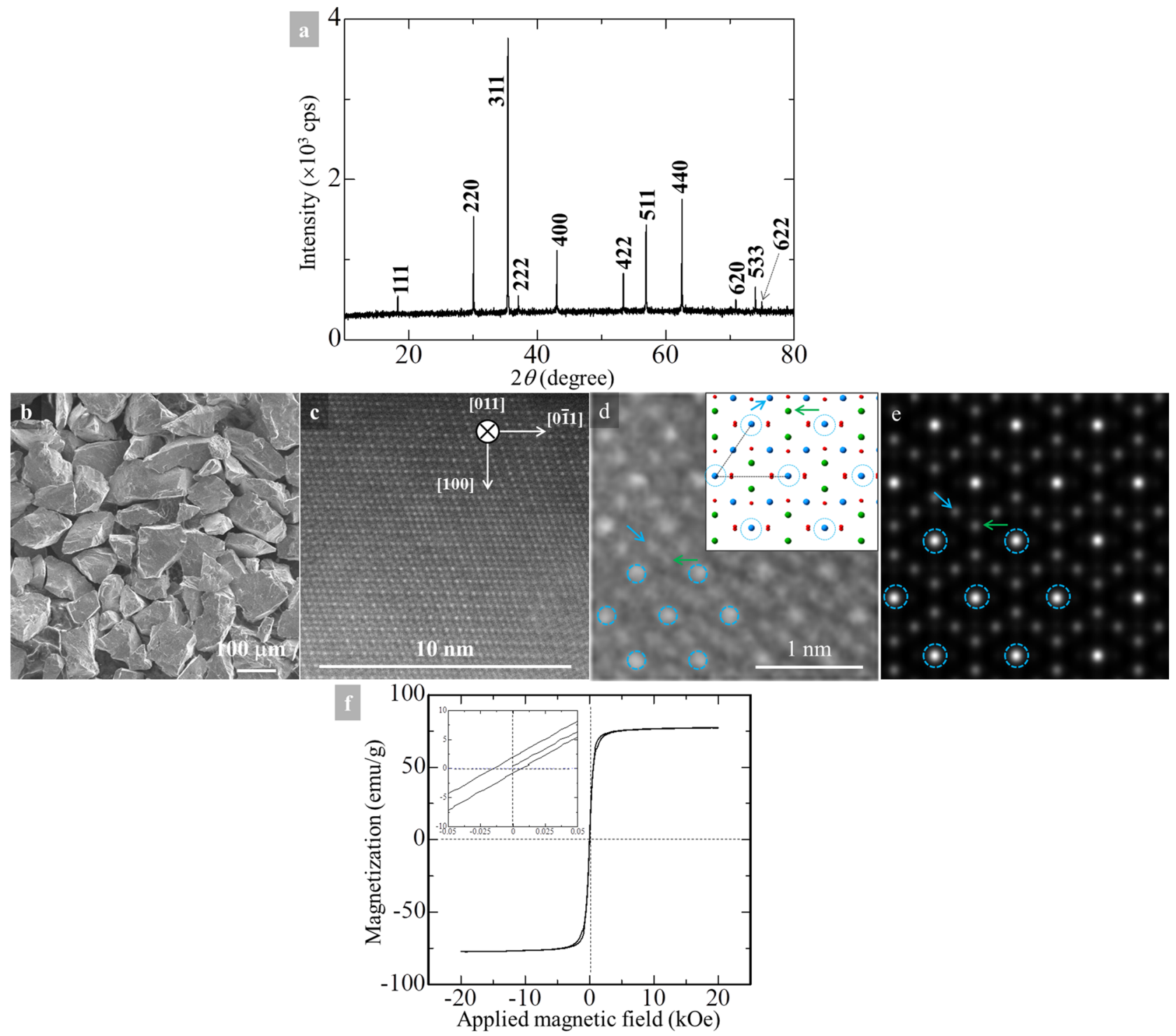

Figure 1. Fundamental characteristics of the $\mathrm{Ni}_{0.5} \mathrm{Zn}_{0.5} \mathrm{Fe}_{2} \mathrm{O}_{4}$ ceramic powder synthesized by a solid-state reaction method after the final heat-treatment. (a) XRD pattern of polycrystalline $\mathrm{Ni}_{0.5} \mathrm{Zn}_{0.5} \mathrm{Fe}_{2} \mathrm{O}_{4}$, (b) FE-SEM and (c) HAADF images of $\mathrm{Ni}_{0.5} \mathrm{Zn}_{0.5} \mathrm{Fe}_{2} \mathrm{O}_{4}$. The HAADF image was taken with an incident electron beam from [011]. (d) is an enlarged image of (c) with simulated atomic positions (insertion). The simulation was based on a reference ${ }^{21}$. Symbols used are as follows; $\mathrm{O}$ (red circles), $A$-site cations at tetrahedrons (green circles), $B$-site cations at octahedrons (blue-dashed circles), another $B$-site cation at octahedron (blue arrow). (e) Simulated diffraction patterns of a spinel-structured ferrite with a thickness of $\sim 4.2 \mathrm{~nm}$. (f) Magnetic hysteresis loop of $\mathrm{Ni}_{0.5} \mathrm{Zn}_{0.5} \mathrm{Fe}_{2} \mathrm{O}_{4}$ ceramic powder measured at room temperature. Inset shows enlarged the vicinity of coercivity.

that the magnetization value shown in Fig. $2 \mathrm{e}$ is normalized. The $\mathrm{Ni}_{0.5} \mathrm{Zn}_{0.5} \mathrm{Fe}_{2} \mathrm{O}_{4}$ ceramic powder exhibited soft magnetic behavior (see Fig. 1f), and the sheet basically repeated this behavior. Indeed, $H_{c}$ values for the $\mathrm{Ni}_{0.5} \mathrm{Zn}_{0.5} \mathrm{Fe}_{2} \mathrm{O}_{4}$-powder/polymer composite sheet are only $12 \mathrm{Oe}$ for parallel, and $17 \mathrm{Oe}$ for perpendicular configurations. There is a configuration dependence for the saturation-magnetic field in Fig. 2e, which suggests a presence of magnetic anisotropy, i.e., that the magnetic easy axis is along the parallel direction in the sheet. The distribution of each $\mathrm{Ni}_{0.5} \mathrm{Zn}_{0.5} \mathrm{Fe}_{2} \mathrm{O}_{4}$ particle is not artificially controlled inside the sheet (see Fig. 2c), so that the magnetic properties of the $\mathrm{Ni}_{0.5} \mathrm{Zn}_{0.5} \mathrm{Fe}_{2} \mathrm{O}_{4}$ particles dispersed in the sheet should vary from particle to particle. The different magnetic behaviors seen in Fig. 2e between the parallel and perpendicular configurations could be induced by a shape anisotropy, which is generated during the sheet preparation by the Doctor-Blade method (see Method section). As a consequence, we infer that the present $\mathrm{Ni}_{0.5} \mathrm{Zn}_{0.5} \mathrm{Fe}_{2} \mathrm{O}_{4}$-powder/polymer composite sheet would be the parallel (in-plane) magnetic anisotropy.

Dynamic physical behavior of the $\mathrm{Ni}_{0.5} \mathrm{Zn}_{0.5} \mathrm{Fe}_{2} \mathrm{O}_{4}$ powder/polymer composite sheet. The complex permeability of the $\mathrm{Ni}_{0.5} \mathrm{Zn}_{0.5} \mathrm{Fe}_{2} \mathrm{O}_{4}$-powder/polymer composite sheet measured by the short-circuited MSL method $^{10,15,19}$ is shown in Fig. $3 \mathrm{a}$ where the real $\left(\mu^{\prime}\right)$ and imaginary $\left(\mu^{\prime \prime}\right)$ parts of the relative permeability are 

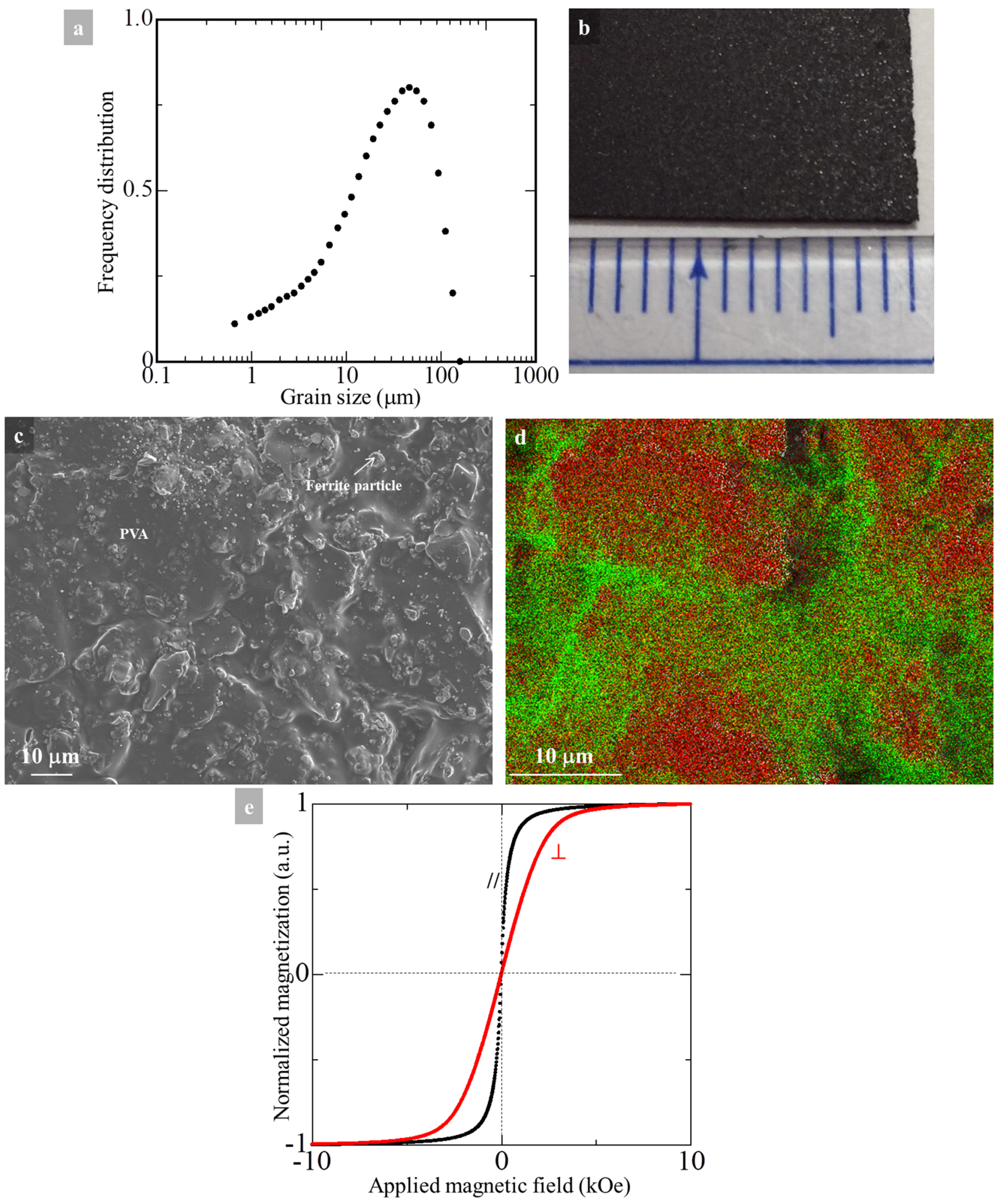

Figure 2. (a) Distribution of particle size of ceramic $\mathrm{Ni}_{0.5} \mathrm{Zn}_{0.5} \mathrm{Fe}_{2} \mathrm{O}_{4}$ powder for the preparation of $\mathrm{Ni}_{0.5} \mathrm{Zn}_{0.5} \mathrm{Fe}_{2} \mathrm{O}_{4}$ powder/polymer composites sheet. (b) The physical appearance of the sheet, and (c) the microstructures of the sheet taken by FE-SEM. The distribution of elements in the sheet is shown in (d). Fe is represented by red color, while green shows the $\mathrm{C}$ distribution. Magnetic hysteresis characteristics of the $\mathrm{Ni}_{0.5} \mathrm{Zn}_{0.5} \mathrm{Fe}_{2} \mathrm{O}_{4}$ powder/polymer composite sheet at room temperature are shown in (e). The external magnetic field is applied normal to the sheet surface (red), whereas the black loop is obtained when the external magnetic field is applied parallel to the surface of the sheet. 

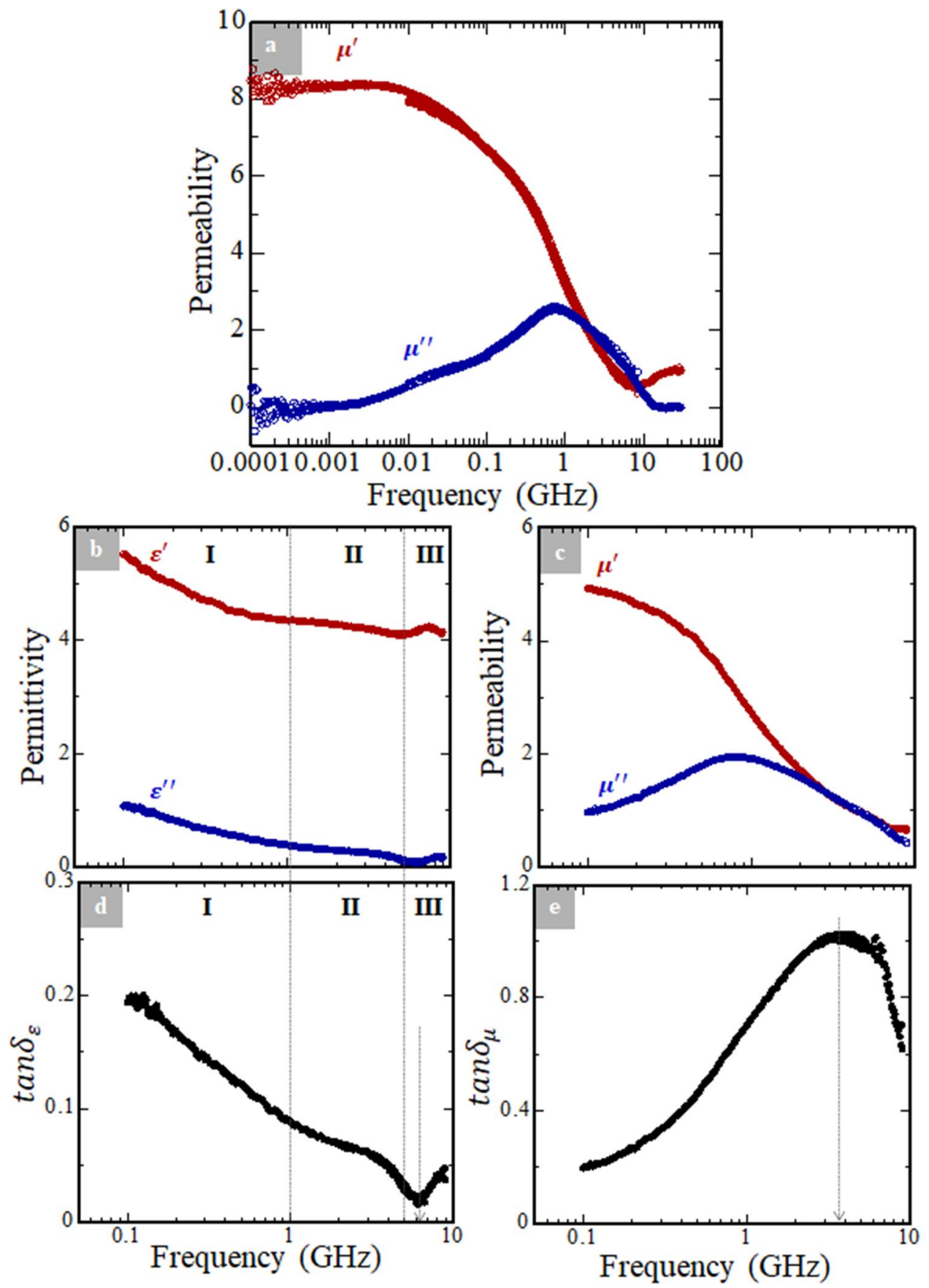

Figure 3. (a) Frequency dependence of dynamic permeability evaluated through the short-circuited MSL method. The maximum frequency of irradiated electromagnetic wave is $30 \mathrm{GHz}$. Frequency dependences of (b) the complex permittivity and (c) the complex permeability measured by means of a network analyzer in the frequency range of $0.1-9 \mathrm{GHz}$. For these measurements, the present $\mathrm{Ni}_{0.5} \mathrm{Zn}_{0.5} \mathrm{Fe}_{\mu^{\prime \prime}} \mathrm{O}_{4}$ powder/polymer composite sheet was fabricated as a toroidal shape. (d) The $\tan \delta_{\varepsilon}=\frac{\varepsilon^{\prime \prime}}{\varepsilon \varepsilon^{\prime}}$, and (e) $\tan \delta_{\mu}=\frac{\mu^{\prime \prime}}{\mu^{\prime}}$, respectively, calculated using the results obtained from $(\mathbf{b})$ and $(\mathbf{c})$, respectively.

plotted against the frequency of electromagnetic wave irradiated up to $30 \mathrm{GHz}$. When increasing the frequency, a gradual decrease was observed in the $\mu^{\prime}-f$ profile, whereas a peak was observed in the $\mu^{\prime \prime}-f$ profile. We define $f_{r}$ as the frequency at the maximum position of the $\mu^{\prime \prime}-f$ curve $\left(\mu_{\max }^{\prime \prime}\right)$. From Fig. $3 \mathrm{a}, f_{r}$ at $\mu_{\max }^{\prime \prime}$ is ca. $7.5 \times 10^{-1} \mathrm{GHz}$. At this frequency, the relative $\mu^{\prime}$ and $\mu^{\prime \prime}$ values of the present sample are 3.4 and 2.6, respectively. For a $0.3\left(\mathrm{Li}_{2} \mathrm{MoO}_{4}\right)-0.7\left(\mathrm{Ni}_{0.5} \mathrm{Zn}_{0.5} \mathrm{Fe}_{2} \mathrm{O}_{4}\right)$ sample mixed with PVA, with a composition similar to the present sheet, the following values were reported: $4.0\left(\mu^{\prime}\right)$ and $1.0\left(\mu^{\prime \prime}\right)^{24}$. Our sample showed 6.8 for $\mu^{\prime}$ and 1.4 for $\mu^{\prime \prime}$ at $0.1 \mathrm{GHz}$, whereas the $0.3\left(\mathrm{Li}_{2} \mathrm{MoO}_{4}\right)-0.7\left(\mathrm{Ni}_{0.5} \mathrm{Zn}_{0.5} \mathrm{Fe}_{2} \mathrm{O}_{4}\right)$ composite exhibited $8.8\left(\mu^{\prime}\right)$ and $0.2\left(\mu^{\prime \prime}\right)$ at the same frequency. Dynamic permeability of the present sheet would be regarded as comparable to that of the 
0.3 $\left(\mathrm{Li}_{2} \mathrm{MoO}_{4}\right)-0.7\left(\mathrm{Ni}_{0.5} \mathrm{Zn}_{0.5} \mathrm{Fe}_{2} \mathrm{O}_{4}\right)$ composite, measured using a different measurement system and method ${ }^{24}$. This confirms the reliability of the present evaluation method.

The high-frequency electromagnetic wave loss phenomena should be addressed. The frequency dependence of the complex permittivity (Fig. 3b) and complex permeability (Fig. 3c) were measured using a network analyzer (ENA E5080A, Keysight Technologies Inc.) on the present sheet sample fabricated in a toroidal shape. We measured in the frequency range of 0.1 to $9 \mathrm{GHz}$ in these experiments. From the obtained permittivity and permeability, the loss tangents, i.e., $\tan \delta_{\varepsilon}=\frac{\varepsilon^{\prime \prime}}{\varepsilon{ }^{\prime}}\left(\right.$ Fig. 3d) and $\tan \delta_{\mu}=\frac{\mu^{\prime \prime}}{\mu^{\prime}}$ (Fig. 3e), respectively, were calculated.

We inferred that the permittivity (Fig. 3b) and $\tan \delta_{\varepsilon}$ (Fig. 3d) can be categorized into three regions, I, II, and III. In the region I, the low frequency range of $f \leq 1 \mathrm{GHz}$, the dispersion of permittivity (Fig. 3b) and $\tan \delta_{\varepsilon}$ (Fig. 3d) rapidly decreased. According to Patil et al. ${ }^{25}$, the decrease in permittivity at low frequencies is attributed to the interfacial polarization between two different phases; $\mathrm{Ni}_{0.5} \mathrm{Zn}_{0.5} \mathrm{Fe}_{2} \mathrm{O}_{4}$ and PVA in the present case. Differing permittivies and conductivities between $\mathrm{Ni}_{0.5} \mathrm{Zn}_{0.5} \mathrm{Fe}_{2} \mathrm{O}_{4}$ and PVA induce space charges under the application of an electric field on the composite sheet. The space charges accumulate at the interface between $\mathrm{Ni}_{0.5} \mathrm{Zn}_{0.5} \mathrm{Fe}_{2} \mathrm{O}_{4}$ and PVA, leading to interfacial polarization ${ }^{25,26}$.

The response time of the interfacial polarization is denoted $\mathrm{as}^{25}$,

$$
\tau=\frac{1}{\omega_{\max }},
$$

where $\omega_{\max }=2 \pi f_{\max }$. In the low frequency region, which corresponds to region $\mathrm{I}$ in this case, $\tau$ is relatively long ${ }^{25}$ according to Eq. (1). Consequently, the decrease in permittivity is prominent in region I. This is the reason for the relatively dull-negative slopes of permittivity (Fig. 3b) and $\tan \delta_{\varepsilon}$ (Fig. 3d) in the range of $1<f \leq 5 \mathrm{GHz}$ (region II), compared with region I.

On the other hand, region III is highly arguable. We observed an anomalous peak in $\varepsilon^{\prime}-f$ profile at $\sim 6.1 \mathrm{GHz}$ (Fig. 3b). The plausible explanation for region III is electron hopping. We previously described that our sample exhibited a high surface resistivity value. However, it does not mean that electrons responsible for conduction of the sample do not exist. Namely, an electron hopping between $\mathrm{Fe}^{2+} / \mathrm{Fe}^{3+}$ and between $\mathrm{Ni}^{3+} / \mathrm{Ni}^{2+}$ could partially account for the conduction ${ }^{25}$, though the conductivity is quite low in our sample. Note that the Mössbauer measurements concluded that the present $\mathrm{Ni}_{0.5} \mathrm{Zn}_{0.5} \mathrm{Fe}_{2} \mathrm{O}_{4}$ ceramic powder exhibited $\mathrm{Fe}^{3+}$ only, but the detection limit of the Mössbauer measurements is approximately $2 \%$ of Fe. Thus, small amounts of $\mathrm{Fe}^{2+}$ could exist in the present sample. When the sample is subjected to high-frequency electromagnetic waves, the electron hopping between $\mathrm{Fe}^{2+} / \mathrm{Fe}^{3+}$ and between $\mathrm{Ni}^{3+} / \mathrm{Ni}^{2+}$ cannot be neglected; the electron hopping between these cation pairs leads to a local displacement of the space charges, resulting in the interfacial polarization in accordance with the direction of the electric field ${ }^{25,27,28}$. When the frequency of irradiated-electromagnetic waves on the sample is increased in region III, the electron hopping would be activated and frequent. Consequently, the interfacial polarization of the sample tends to be increased. After passing through the "critical frequency" at $\sim 6.1 \mathrm{GHz}$, the electron hopping cannot follow the alternating electric field any more ${ }^{26}$, which leads to an abrupt deterioration of permittivity (Fig. 3b). This could be the reason for the anomalous peak ${ }^{25}$ in Fig. $3 \mathrm{~b}$, while a minimum value was observed in Fig. $3 \mathrm{~d}$ owing to an inverse relationship between $\varepsilon^{\prime}$ and $\tan \delta_{\varepsilon}$. We speculate that the anomalous peak in $\varepsilon^{\prime}-f$ profile in category III (Fig. 3b) is due to the electron hopping.

We further measured frequency dependence of permeability (Fig. 3c) to discuss the magnetic loss, $\tan \delta_{\mu}$ (Fig. 3e). We obtained the maximum $\tan \delta_{\mu}$ value of approximately 1.0 at $\sim 3.6 \mathrm{GHz}$ (Fig. 3e). As is generally recognized, $\tan \delta_{\mu}$ of magnetic materials consists of the sum of eddy-current loss $\left(\tan \delta_{e}\right)$, hysteresis $\operatorname{loss}\left(\tan \delta_{h}\right)$ and remanent loss $\left(\tan \delta_{r}\right)$. As previously mentioned, the influence of $\tan \delta_{e}$ is negligible for the present sheet. Thus, we consider only $\tan \delta_{h}$ and $\tan \delta_{r}$.

To discuss $\tan \delta_{h}$, we must consider the stress sensitivity of the samples. In general, stresses such as magnetostriction, compressive and tensile stresses of magnetic materials cause stress-induced deformation of the hysteresis loops, which give rise to a non-zero $\tan \delta_{h}^{29,30}$ in the high-frequency band. For polycrystalline samples, the stress effects and hence also $\tan \delta_{h}$ are complicated because various types of stresses are possible with random directions ${ }^{31}$. When we prepared the $\mathrm{Ni}_{0.5} \mathrm{Zn}_{0.5} \mathrm{Fe}_{2} \mathrm{O}_{4}$-powder/polymer composite sheet, we ground the $\mathrm{Ni}_{0.5} \mathrm{Zn}_{0.5} \mathrm{Fe}_{2} \mathrm{O}_{4}$ ceramic powder sufficiently to attain fine $\mathrm{Ni}_{0.5} \mathrm{Zn}_{0.5} \mathrm{Fe}_{2} \mathrm{O}_{4}$ particles. It is possible that this procedure could generate some internal stresses on the $\mathrm{Ni}_{0.5} \mathrm{Zn}_{0.5} \mathrm{Fe}_{2} \mathrm{O}_{4}$ particles. On the other hand, mechanical or electric stresses were not applied for the present sample, so that the present sheet should be free from external stresses. $\tan \delta_{h}$ consists of the sum of internal and external stresses, but the areas of the hysteresis loops of the sheet (Fig. 2e) are small. Hence, an influence of $\tan \delta_{h}$ is rather small for the present case.

For $\tan \delta_{r}$, the resonance linewidths of the $\mu^{\prime}-f$ and $\mu^{\prime \prime}-f$ profiles are good indicators, because the linewidths determine the amount of $\tan \delta_{r}{ }^{31}$. It has been reported that four independent factors determine the resonance linewidths, and hence $\tan \delta_{r}$ : (1) spin-lattice relaxation, (2) porosity and/or nonmagnetic inclusions, (3) magnetocrystalline anisotropy, and (4) surface roughness. (2) plays the role of local demagnetization centers to induce demagnetization effects owing to inhomogeneous internal magnetic fields. This results in broadening of the resonance linewidths ${ }^{32,33}$. We infer that (2) would be the most probable origin of $\tan \delta_{r}$ for the present composite material among these four factors.

As a conclusion, the $\tan \delta_{\mu}$ value in the present $\mathrm{Ni}_{0.5} \mathrm{Zn}_{0.5} \mathrm{Fe}_{2} \mathrm{O}_{4}$-powder/polymer composite sheet (Fig. 3e) could be mainly due to $\tan \delta_{r}$, which is caused by (2). In this study, we achieved dynamic-physical behavior for our $\mathrm{Ni}_{0.5} \mathrm{Zn}_{0.5} \mathrm{Fe}_{2} \mathrm{O}_{4}$-powder/polymer composite sheet comparable to that previously reported for a material with essentially similar composition ${ }^{24}$, except the $\tan \delta_{\mu}$ value of $\sim 1.0$ in the vicinity of $\sim 3.6 \mathrm{GHz}$ (Fig. 3e). To overcome large loss tangents, the formation of epitaxially-grown single-crystal $\mathrm{Ni}_{0.5} \mathrm{Zn}_{0.5} \mathrm{Fe}_{2} \mathrm{O}_{4}$ films on the flexible underlayers could be a solution. 

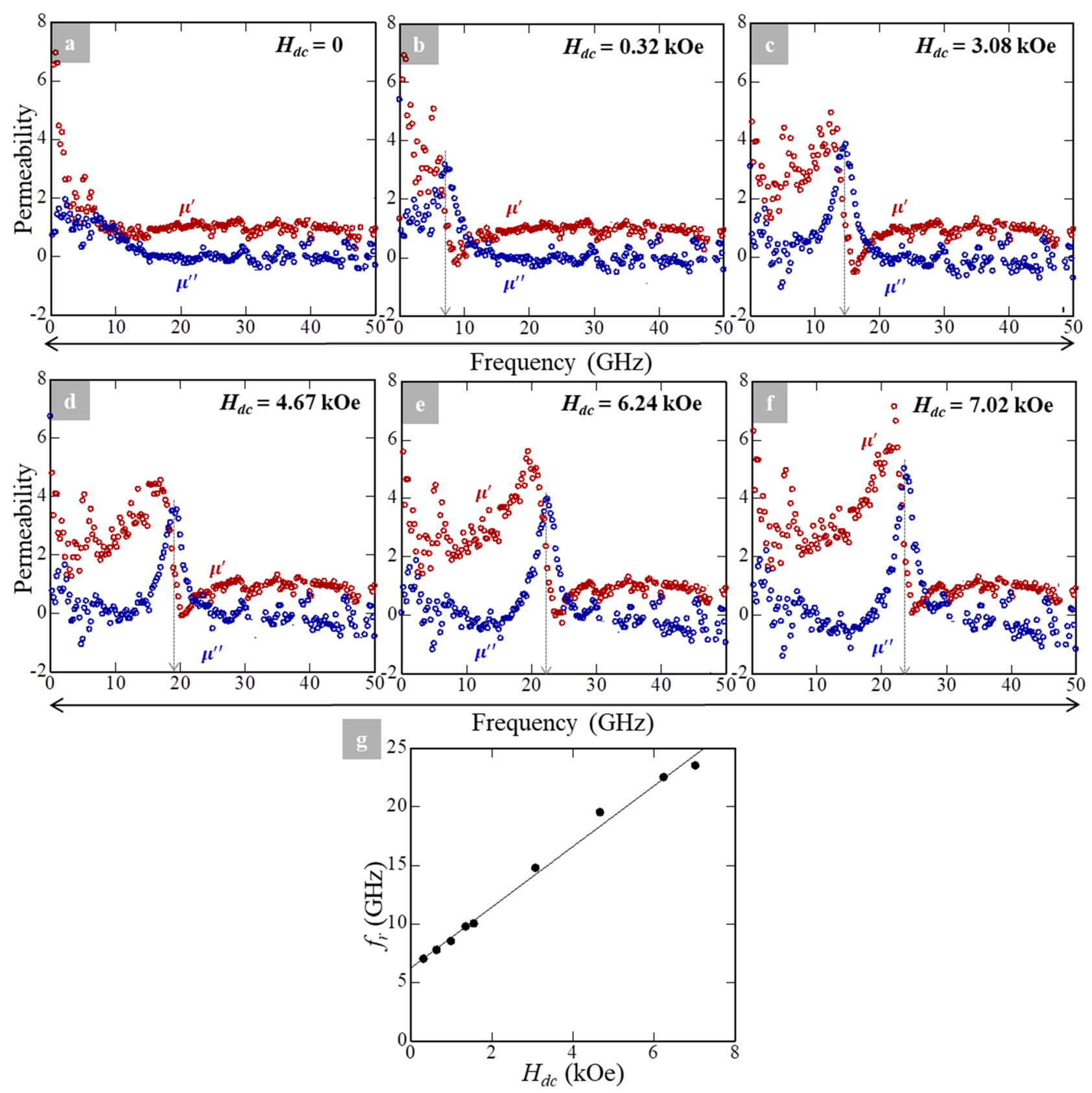

Figure 4. Frequency dependence of dynamic permeability obtained by the MSL-probe method up to $50 \mathrm{GHz}$. The external magnetic DC field $\left(H_{d c}\right)$ applied during the measurements is (a) 0, (b) 0.32, (c) 3.08, (d) 4.67, (e) 6.24 , and (f) $7.02 \mathrm{kOe}$, respectively. (g) The relationship between $f_{r}$ and $H_{d c}$ based on the results form measurements with a linear fit.

We also evaluated the complex permeability by the MSL-probe method, (ii). Although the methods (i) and (ii) represent different approaches (see Method section), we emphasize that the dynamic $\mu^{\prime}-f$ and $\mu^{\prime \prime}-f$ behaviors were essentially consistent. In the MSL-probe method, we applied a strong static external magnetic field, $H_{d c}$, on the sheet sample during the measurements. The strength of $H_{d c}$ was controlled by changing the strength of an applied DC current with/without using yokes. As a consequence, $H_{d c}$ was varied from 0 to $\sim 7 \mathrm{kOe}$. In this case, $H_{d c}$ was applied parallel to a high frequency-alternating current (AC), $I_{r f}$, which propagates along the MSL. As a result, the configuration of the directions among longitudinal direction of the rectangle-shaped sheet sample, $H_{d c}$, and $I_{r f}$ are parallel. Figure $4 \mathrm{a}-\mathrm{f}$ show the results of the $\mu^{\prime}-f$ and $\mu^{\prime \prime}-f$ behaviors upon applying various $H_{d c}$ fields obtained by method (ii). In contrast to Fig. 3a, these figures are plotted with a linear scale for the $\mathrm{X}$-axis. The maximum frequency value of electromagnetic wave irradiated for these measurements is $50 \mathrm{GHz}$.

Note that the measurement condition of Fig. $3 \mathrm{a}$ is the same as that of Fig. $4 \mathrm{a}\left(H_{d c}=0\right)$. Upon increasing $H_{d c}$, the position of $\mu_{\max }^{\prime \prime}$ (indicated by dashed arrows) shifted towards higher frequencies. Changes in $f_{r}$ as a function of $H_{d c}$ are summarized in Fig. 4g; we clarified the apparent shift of FMR through $H_{d c}$. From Fig. 4g, the relationship between $f_{r}$ and $H_{d c}$ assuming a linear relation is: 


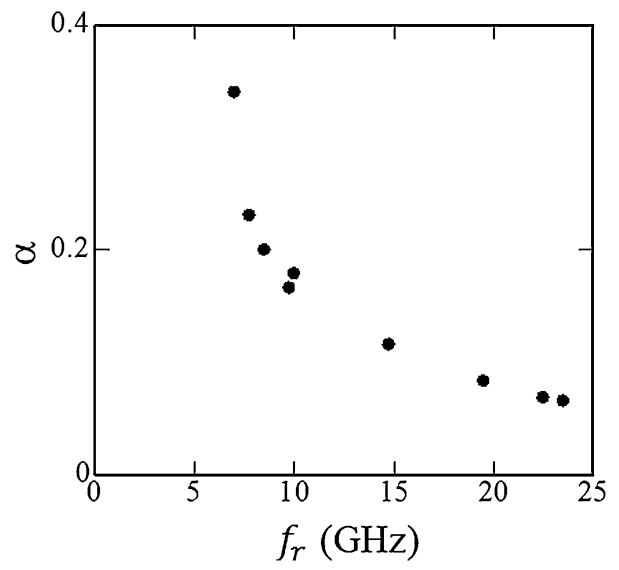

Figure 5. Gilbert damping constant, $\alpha$, as a function of the resonance frequency $\left(f_{r}\right) . f_{r}$ values are obtained from Fig. $4 \mathrm{~g}$. On the other hand, $\alpha$ values are determined by the $\mu^{\prime \prime}-f$ profiles from method (ii) using Eq. (3).

$$
f_{r(c a l)}=2.59 H_{d c}+6.25
$$

with a reliability value, $|r|$, of $9.96 \times 10^{-1}$. The linear relationship between $f_{r(c a l)}$ and $H_{d c}$ in Fig. $4 \mathrm{~g}$ is reasonable from the perspective of the FMR theory reported by Kittel ${ }^{34}$. In the present case, the linearity is concluded for the entire range of $H_{d c}$ (Fig. $4 \mathrm{~g}$ ), such that $\mathrm{Ni}_{0.5} \mathrm{Zn}_{0.5} \mathrm{Fe}_{2} \mathrm{O}_{4}$-powder/polymer composite sheet could be applicable in a wide range of $\mathrm{GHz}$-operational frequencies ${ }^{35}$ even at small $H_{d c}$.

From Eq. (2), the value of $f_{r(c a l)}$ is determined to be $6.25 \mathrm{GHz}$ at $H_{d c}=0$. However, we did not observe any apparent $\mu_{\text {max }}^{\prime \prime}$ in Fig. $4 \mathrm{a}\left(H_{d c}=0\right)$, and hence the determination of $f_{r}$ is impossible from Fig. 4a. This is contradictory to the experiment (Fig. 4a) and the mathematical extrapolation [Eq. (2)]. We should also mention that the $f_{r}$ value is estimated to be $7.5 \times 10^{-1} \mathrm{GHz}$ from Fig. $3 \mathrm{a}\left(H_{d c}=0\right)$; this is the only difference between methods (i) and (ii), which reveals the difficulties of precise evaluations under $\mathrm{GHz}$-frequency bands.

We studied a relationship between the Gilbert damping constant, $\alpha$, and $f_{r}$ (Fig. 5). For this discussion, $f_{r}$ values were obtained from Fig. $4 \mathrm{~g}$, whereas a values were determined by the $\mu^{\prime \prime}-f$ profiles obtained by method (ii). We utilized following equation ${ }^{36}$ for calculating the damping constant,

$$
\alpha=\frac{\Delta f}{f_{r}} .
$$

$\Delta f$ is denoted as $\frac{1}{2} \times$ (full width at half maximum of the $\mu^{\prime \prime}-f$ peak).

From Fig. 5, we found that the damping constant drastically decreased as $f_{r}$ increases (increases in $H_{d c}$ ). The $\alpha_{\max }$ value is $3.40 \times 10^{-1}$ at $f_{r}=7.01 \mathrm{GHz}\left(H_{d c}=3.20 \times 10^{-1} \mathrm{kOe}\right.$, which corresponds to Fig. $\left.4 \mathrm{~b}\right)$, while the value of $\alpha_{\min }$ is $6.52 \times 10^{-2}$ at $f_{r}=2.35 \times 10 \mathrm{GHz}\left(H_{d c}=7.02 \mathrm{kOe}\right.$ corresponding to Fig. $\left.4 \mathrm{f}\right)$. In epitaxiallygrown spinel ferrite films with the chemical formula of $\mathrm{Ni}_{0.65} \mathrm{Zn}_{0.35} \mathrm{Al}_{0.8} \mathrm{Fe}_{1.2} \mathrm{O}_{4}$ possessing a similar composition as the present sample, low damping constant values have been reported; $2.6 \times 10^{-3} \leq \alpha \leq 3.5 \times 10^{-337}$. These values are one-to-two orders of magnitude lower than our sample.

A magnetic-based material exhibiting a high $\alpha$ value implies that the FMR phenomenon of the sample is complicated $^{38}$. In the case of spinel-structured ferrite films, the constituent of cations ${ }^{39}$ and high density of crystal defects generated by dislocations and/or antiphase boundaries ${ }^{40-42}$ affect the damping. This results in a defect-mediated damping ${ }^{37}$. These factors are potentials for "extrinsic" damping, which leads to high $\alpha$ value ${ }^{43-48}$. However, from microstructural investigations in this study, we observed neither remarkable antiphase boundaries nor misfit dislocations (Fig. 1c-e). In the magnetic field dependent magnetization behaviors, the structural defects such as antiphase boundaries and so on could lead to a large $H_{c}$ value and "S-shaped" hysteresis curve $e^{49}$, but we obtained a rather small value for $H_{c}$ as well as "regular-shaped" hysteresis curves (Figs. 1f and 2e). By considering these experimental facts, we can eliminate the possibility of defect-mediated damping behind the high $\alpha$ values in the present case.

By taking into account the discussions above, we suggest that the damping of the present $\mathrm{Ni}_{0.5} \mathrm{Zn}_{0.5} \mathrm{Fe}_{2} \mathrm{O}_{4}$ powder/polymer composite sheet could be largely related to the $3 d$ electrons from $\mathrm{Fe}$ and $\mathrm{Ni}$ atoms. Although further detailed studies are necessary, intuitive considerations would be possible; the coupling between $3 d$ electrons, $3 d$ spins, and phonons is sufficiently strong to induce high $\alpha$ values ${ }^{38}$ in the present $\mathrm{Ni}_{0.5} \mathrm{Zn}_{0.5} \mathrm{Fe}_{2} \mathrm{O}_{4}$ powder/polymer composite sheet. In the epitaxially-grown spinel structured $\mathrm{MgFe}_{2} \mathrm{O}_{4}$ thin film deposited on $\mathrm{MgAl}_{2} \mathrm{O}_{4}(100)$ substrate, the $\alpha$ value was reported to be approximately $8 \times 10^{-249}$. Our $\alpha_{\min }$ value $\left(6.52 \times 10^{-2}\right.$ at $f_{r}=2.35 \times 10 \mathrm{GHz}$ with the application $H_{d c}$ of $\left.7.02 \mathrm{kOe}\right)$ is comparable to that value ${ }^{49}$, though the present sheet consists of polycrystalline $\mathrm{Ni}_{0.5} \mathrm{Zn}_{0.5} \mathrm{Fe}_{2} \mathrm{O}_{4}$ particles.

Therefore, the significance of the present study is the high potential of the present $\mathrm{Ni}_{0.5} \mathrm{Zn}_{0.5} \mathrm{Fe}_{2} \mathrm{O}_{4}$ powder/ polymer composite sheet composed of an environmentally friendly ferrite with cost-effective elements applicable 
over $\mathrm{GHz}$ bands. Another prominent significance of this study is showing the reliability of the novel evaluation methods (i) and (ii). This study gives hope for the establishment of high-frequency technologies beyond several tens of $\mathrm{GHz}$ bands.

\section{Conclusions}

In conclusion, we applied two different originally developed techniques, short-circuited MSL ${ }^{10,15,19}$ and MSL-probe ${ }^{11,20}$ methods, to a $\mathrm{Ni}_{0.5} \mathrm{Zn}_{0.5} \mathrm{Fe}_{2} \mathrm{O}_{4}$ powder/polymer composite sheet prepared from high-quality $\mathrm{Ni}_{0.5} \mathrm{Zn}_{0.5} \mathrm{Fe}_{2} \mathrm{O}_{4}$ ceramic powder. Although the two techniques are based on different experimental setups/systems, the dynamic permeability behaviors at $\mathrm{GHz}$ bands are essentially consistent.

A linear relationship between $f_{r(c a l)}$ and $H_{d c}$ was obtained for the entire measured range, up to $50 \mathrm{GHz}$. The linearity between $f_{r(c a l)}$ and $H_{d c}$ at sufficiently small required $H_{d c}$ suggests that the present sheet has potential applications to power-efficient devices ${ }^{37}$. Further study on the damping is necessary, but the damping process of the current $\mathrm{Ni}_{0.5} \mathrm{Zn}_{0.5} \mathrm{Fe}_{2} \mathrm{O}_{4}$ powder/polymer composite sheet could be dominated by a strong coupling between $3 d$ electrons, $3 d$ spins, and phonons.

Although the present sheet is composed of polycrystalline $\mathrm{Ni}_{0.5} \mathrm{Zn}_{0.5} \mathrm{Fe}_{2} \mathrm{O}_{4}$, the sheet showed soft magnetism exhibiting parallel magnetic anisotropy, high surface resistivity, small required $H_{d c}$ for FMR, an intrinsic damping process, and comparable damping constant to the epitaxially-grown thin film ${ }^{49}$. These results indicate that highperformance devices that can be utilized in frequency bands up to several tens of GHz. For example, the present $\mathrm{Ni}_{0.5} \mathrm{Zn}_{0.5} \mathrm{Fe}_{2} \mathrm{O}_{4}$-powder/polymer composite sheet is magnetically anisotropy, such that "anisotropic suppression" of electromagnetic waves with $\mathrm{GHz}$ frequencies could be possible ${ }^{50}$; the present sample can be expected to be useful as an anisotropic-EMI material in the $\mathrm{GHz}$ band, which is essential for high-frequency electronic devices.

\section{Methods}

Synthesis of impurity-free spinel-structured $\mathrm{Ni}_{0.5} \mathrm{Zn}_{0.5} \mathrm{Fe}_{2} \mathrm{O}_{4}$ powder. In the present study, $\mathrm{Ni}_{0.5} \mathrm{Zn}_{0.5} \mathrm{Fe}_{2} \mathrm{O}_{4}$ powder was mixed with a polymer to attain a $\mathrm{Ni}_{0.5} \mathrm{Zn}_{0.5} \mathrm{Fe}_{2} \mathrm{O}_{4}$ powder/polymer composite sheet. First of all, $\mathrm{Ni}_{0.5} \mathrm{Zn}_{0.5} \mathrm{Fe}_{2} \mathrm{O}_{4}$ ceramic powder was synthesized by a solid-state reaction method. High purity starting materials, i.e., stoichiometric quantities of $\alpha-\mathrm{Fe}_{2} \mathrm{O}_{3}$ (99.9\%), $\mathrm{NiO}$ (99.97\%), and $\mathrm{ZnO}$ (99.999\%), were mixed and calcined in air at $1000{ }^{\circ} \mathrm{C}$ for $4 \mathrm{~h}$. The calcined powder was ground and pressed to pellets with the diameter of $10 \mathrm{~mm}$, by applying a mechanical pressure of $10 \mathrm{MPa}$. Finally, the pelletized sample was annealed in air at $1400{ }^{\circ} \mathrm{C}$ for $4 \mathrm{~h}$. The annealing temperature was chosen to achieve the most superior sample quality. To avoid peroxidation, we annealed the sample in air instead of an $\mathrm{O}_{2}$ atmosphere.

Preparation of $\mathrm{Ni}_{0.5} \mathrm{Zn}_{0.5} \mathrm{Fe}_{2} \mathrm{O}_{4}$ powder/polymer composite sheet by the Doctor-Blade method. The pelletized $\mathrm{Ni}_{0.5} \mathrm{Zn}_{0.5} \mathrm{Fe}_{2} \mathrm{O}_{4}$ after the final annealing was ground carefully using a grinder to obtain $\mathrm{Ni}_{0.5} \mathrm{Zn}_{0.5} \mathrm{Fe}_{2} \mathrm{O}_{4}$ particles with a homogeneous size-distribution. We classified the $\mathrm{Ni}_{0.5} \mathrm{Zn}_{0.5} \mathrm{Fe}_{2} \mathrm{O}_{4}$ particles using sieves with different mesh sizes. After that, the $\mathrm{Ni}_{0.5} \mathrm{Zn}_{0.5} \mathrm{Fe}_{2} \mathrm{O}_{4}$ powder with homogeneous size was mixed with a PVA $\left(-\left(\mathrm{CH}_{2} \mathrm{CH}(\mathrm{OH})-\right)_{500}\right)$ solution. The ceramic $\mathrm{Ni}_{0.5} \mathrm{Zn}_{0.5} \mathrm{Fe}_{2} \mathrm{O}_{4}$ powder and PVA solution were well mixed in a crucible, resulting in slurry with proper viscosity. By spreading the slurry on a flat PET-film and applying the Doctor-Blade method, we obtained sheet-shaped $\mathrm{Ni}_{0.5} \mathrm{Zn}_{0.5} \mathrm{Fe}_{2} \mathrm{O}_{4}$ powder/polymer composite. After drying the sheet under ambient conditions in air, the sheet was removed from PET film, and was heat-treated to dry completely at $105^{\circ} \mathrm{C}$ for $1 \mathrm{~h}$; this is a monolayered sheet with the thickness of $166 \mu \mathrm{m}$ on the average. Afterward, we piled two monolayered sheets, and performed a heat treatment at $150{ }^{\circ} \mathrm{C}$ for 6 min by applying a mechanical pressure to attain higher density of the $\mathrm{Ni}_{0.5} \mathrm{Zn}_{0.5} \mathrm{Fe}_{2} \mathrm{O}_{4}$ powder/polymer composite sheet. We focus only on the double-layered $\mathrm{Ni}_{0.5} \mathrm{Zn}_{0.5} \mathrm{Fe}_{2} \mathrm{O}_{4}$ powder/polymer composite sheet instead of a monolayered one in this study.

Fundamental characterizations. The phase purity and crystallinity were evaluated by X-ray diffraction (XRD, SmartLab, Rigaku Corporation). The magnetic field dependent magnetization behaviors were measured in the range of $\pm 10 \mathrm{kOe}$ at room temperature using a vibrating sample magnetometer (VSM, C7-10A, Toei Industry Co., Ltd.). The $\mathrm{Ni}_{0.5} \mathrm{Zn}_{0.5} \mathrm{Fe}_{2} \mathrm{O}_{4}$ powder was embedded in a polymer matrix (Pattex $100 \%$ glue, Henkel) on a Fe-free $\mathrm{Al}$ foil, and room-temperature ${ }^{57} \mathrm{Fe}$ Mössbauer spectra were collected at $12 \mathrm{~mm} / \mathrm{s}$ (FGX-222ST Mössbauer spectrometer, Topologic Systems Inc.) using a $50 \mathrm{mCi}$ Cyclotron ${ }^{57} \mathrm{Co} / \mathrm{Rh}$ source. The microscopic crystal structures of the sample were observed by field-emission scanning electron microscopy (FE-SEM, JSM7000F, JEOL Ltd.) and field-emission transmission electron microscopy (FE-TEM, JEM-ARM200F, JEOL Ltd.), respectively.

Evaluations of dynamic permeability in the $\mathrm{GHz}$-frequency region. For the dynamic permeability in the GHz-frequency region, (i) short-circuited $\mathrm{MSL}^{10,15,19}$ and (ii) MSL-probe ${ }^{11,20}$ methods were employed and their results were compared. In the case of (i), originally developed sample jigs were used to produce electromagnetic radiation of suitable frequencies to irradiate the sample for the measurements. The sheet sample was cut into a rectangle and placed at the short end of the MSL. In method (i), a sufficiently strong $H_{d c}$ was applied to saturate the $\mathrm{Ni}_{0.5} \mathrm{Zn}_{0.5} \mathrm{Fe}_{2} \mathrm{O}_{4}$ powder/polymer composite sheet using a permanent magnet (Fig. $3 \mathrm{a}$ ). $I_{r f}$, AC with high frequency, was propagated along the MSL, such that an AC magnetic field, $H_{r f}$, is generated perpendicular to the direction of the $I_{r f}$. In this method, we regarded the overall experimental system as an "electric circuit model" including the sample and the jigs ${ }^{10,15,19}$. We attained one of the scattering matrixes of an electric circuit, $S_{11}$ as an output signal from the measurements in this method. Using $S_{11}$, the admittance, $Y_{1}$, of the electric circuit can be calculated. $H_{d c}$ was applied parallel to the longitudinal direction of the rectangle-shaped sheet sample. Therefore, the direction of $H_{d c}$ is perpendicular to $I_{r f}$. Under the application of $H_{d c}$, the electric circuit model of 
the experimental system changes, so that $Y_{1}$ is replaced by $Y_{2}{ }^{10,15,19}$. By the use of $Y_{1}$ and $Y_{2}$, we can determine the relative values of complex permeability of the sample. The details of the method and calculation procedures are mentioned elsewhere $\mathrm{e}^{10,15,19}$.

In method (ii), a "self-developed" probe composed of a MSL on a flexible substrate was used for the measurements ${ }^{11,20}$. The MSL probe was set on the surface of sheet sample with a gap between the sample and the probe of approximately $200 \mu \mathrm{m}$. Before the measurements, a calibration of the network analyzer had been carefully performed by applying $H_{d c} \approx 8 \mathrm{kOe}$ without the sample. Non-magnetic signals were perfectly subtracted from coaxial cables and jigs throughout the calibration. Similar to method (i), we applied sufficiently strong $H_{d c}$ after the sheet sample was placed in the measurement device in the method (ii). This procedure enables us to saturate the specimen ${ }^{20}$. After that, the permeability measurements were carried out. In this method, the overall experimental system is also regarded as an electric circuit model. The output signal from the measurements is $S_{21}$, which is one of the other scattering matrixes of an electric circuit. Using the obtained $S_{21}$, we can determine the relative values of complex permeability of the sample. For the details of method (ii), refer to literatures ${ }^{11,20}$.

\section{Data availability}

All data generated or analyzed during this study are included in this published article.

Received: 22 May 2020; Accepted: 14 December 2020

Published online: 12 January 2021

\section{References}

1. Ide, T. et al. Reduction of radiated emission from resonance coil in GaN wireless power transmission circuit by using $\mathrm{Nd}-\mathrm{Fe}-\mathrm{N}$ magnetic material. AIP Adv. 10, 025121-1-025121-5 (2020).

2. Abeywickrama, N., Serdyuk, Y. V. \& Gubanski, S. M. High-frequency modeling of power transformers for use in frequency resonance analysis (FRA). IEEE Trans. Powder Del. 23, 2042-2049 (2008).

3. Takeda, S., Hotchi, T., Motomura, S. \& Suzuki, H. Theoretical consideration on short- \& open-circuited transmission lines for permeability \& permittivity measurement. J. Magn. Soc. Jpn. 39, 116-120 (2015).

4. Sato, T., Sato, K., Yamasawa, K., Zhang, F. \& Yanagisawa, K. Spiral-type transmission line with an Mn-Zn ferrite core. IEEE Trans. Magn. 39, 3205-3207 (2003).

5. Sato, K., Sato, T., Yamasawa, K., Zhang, F. \& Yanagisawa, K. Equivalent circuit analysis of spiral-type transmission line with Mn-Zn ferrite core. J. Magn. Soc. Jpn. 28, $731-737$ (2004) ((in Japanese)).

6. Nicolson, A. M. \& Ross, G. F. Measurement of the intrinsic properties of materials by time-domain techniques. IEEE Trans. Instrum. Meas. IM-19, 377-382 (1970).

7. Weir, W. B. Automatic measurement of complex dielectric constant and permeability at microwave frequencies. Proc. IEEE 62, 33-36 (1974).

8. Okayama, K. et al. Electromagnetic wave absorption properties of $\mathrm{BaFe}_{12-\mathrm{x}}\left(\mathrm{Ti}_{0.5} \mathrm{M}_{0.5}\right)_{\mathrm{x}} \mathrm{O}_{19}(\mathrm{M}=\mathrm{Co}, \mathrm{Ni}, \mathrm{Zn}, \mathrm{Mn}, \mathrm{Cu})$. J. Magn. Soc. Jpn. 22, 297-300 (1998) (in Japanese).

9. Yoshida, S. et al. Crystal structure and microwave permeability of very thin $\mathrm{Fe}-\mathrm{Si}-\mathrm{Al}$ flakes produced by microforging. J. Appl. Phys. 93, 6659-6661 (2003).

10. Takeda, S., Hotchi, T., Motomura, S. \& Suzuki, H. Permeability measurements of magnetic thin films using shielded short-circuited microstrip lines. J. Magn. Soc. Jpn. 39, 227-231 (2015).

11. Yabukami, S. et al. Permeability measurements of thin film using a flexible microstrip line-type probe up to $40 \mathrm{GHz}$. J. Magn. Soc. Jpn. 41, 25-28 (2017).

12. Snoek, J. L. Gyromagnetic resonance in ferrites. Nature 160, 90 (1947).

13. Thompson, S., Shirtcliffe, N. J., O'Keefe, E. S., Appleton, S. \& Perry, C. C. Synthesis of $\operatorname{SrCo}_{\mathrm{x}} \mathrm{Ti}_{\mathrm{x}} \mathrm{Fe}_{(12-2 \mathrm{x})} \mathrm{O}_{19}$ through sol-gel autoignition and its characterization. J. Magn. Magn. Mater. 292, 100-107 (2005).

14. Nie, Y., Harward, I., Balin, K., Beaubien, A. \& Celinski, Z. Preparation and characterization of barium hexagonal ferrite thin films on a Pt template. J. Appl. Phys. 107, 073903-1-073903-5 (2010).

15. Sai, R., Sato, M., Takeda, S., Yabukami, S. \& Yamaguch, M. Co/Ti-substituted SrM-based composite sheets: high frequency permeability and electromagnetic noise suppression above 6 GHz. J. Magn. Magn. Mater. 459, 49-56 (2018).

16. Jalli, J. et al. Magnetic and microwave properties of Sm-doped $\mathrm{SrFe}_{12} \mathrm{O}_{19}$ single crystals. IEEE Trans. Magn. 44, 2978-2981 (2008).

17. Sugimoto, S., Okayama, K., Kondo, S., Ota, H., Kimura, M., Yoshida, Y., Nakamura, H., Book, D., Kagotani, T. \& Homma, M. Barium M-type ferrite as an electromagnetic microwave absorber in the GHz range. Mater. Trans. JIM 39, 1080-1083 (1998).

18. Yoshida, S., Sato, M., Sugawara, E. \& Shimada, Y. Permeability and electromagnetic-interference characteristics of Fe-Si-Al alloy flakes-polymer composite. J. Appl. Phys. 85, 4636-4638 (1999).

19. Takeda, S. \& Naoe, M. Techniques for measuring complex permeability in SHF band. Magn. Jpn. 14, 12-19 (2019) ((in Japanese)).

20. Yabukami, S., Nozawa, K., Tonthat, L., Okita, K. \& Sai, R. Impact of complex permeability measurements up to millimeter-wave frequency range. IEEE Trans. Magn. https://doi.org/10.1109/TMAG.2020.3011971 (2020).

21. Shirsath, S. E., Patange, S. M., Kadam, R. H., Mane, M. L. \& Jadhav, K. M. Structure refinement, cation site location, spectral and elastic properties of $\mathrm{Zn}^{2+}$ substituted $\mathrm{NiFe}_{2} \mathrm{O}_{4}$. J. Mol. Struct. 1024, 77-83 (2012).

22. Albuquerque, A. S., Ardisson, J. D., Macedo, W. A. A. \& Alves, M. C. M. Nanosized powders of NiZn ferrite: synthesis, structure, and magnetism. J. Appl. Phys. 87, 4352-4357 (2000).

23. Deka, S. \& Joy, P. A. Characterization of nanosized NiZn ferrite powders synthesized by an autocombustion method. Mater. Chem. Phys. 100, 98-101 (2006).

24. He, L., Zhou, D., Yang, H., Niu, Y., Xiang, F. \& Wang, H. Low-temperature sintering $\mathrm{Li}_{2} \mathrm{MoO}_{4} / \mathrm{Ni}_{0.5} \mathrm{Zn}_{0.5} \mathrm{Fe}_{2} \mathrm{O}_{4}$ magneto-dielectric composites for high-frequency application. J. Am. Ceram. Soc. 97, 2552-2556 (2014).

25. Patil, D. R., Lokare, S. A., Chougule, S. S. \& Chougule, B. K. Dielectric and magnetic properties of $x \mathrm{NiFe}_{2} \mathrm{O}_{4}+(1-x) \mathrm{Ba}_{0.9} \mathrm{Sr}_{0.1} \mathrm{TiO}_{3}$ composites. Physica B 400, 77-82 (2007).

26. Yue, Z., Zhou, J., Gui, Z. \& Li, L. Magnetic and electrical properties of low-temperature sintered Mn-doped NiCuZn ferrites. J. Magn. Magn. Mater. 264, 258-263 (2003).

27. Ranga Mohan, G., Ravinder, D., Ramana Reddy, A. V. \& Boyanov, B. S. Dielectric properties of polycrystalline mixed nickel-zinc ferrites. Mater. Lett. 40, 39-45 (1999).

28. Watawe, S. C., Sarwade, B. D., Bellad, S. S., Sutar, B. D. \& Chougule, B. K. Microstructure, frequency and temperature-dependent dielectric properties of cobalt-substituted lithium ferrites. J. Magn. Magn. Mater. 214, 55-60 (2000).

29. Stern, E. \& Temme, D. Magnetostriction effects in remanence phase shifters. IEEE Trans. Microw. Theory Tech. 13, 873-874 (1965).

30. Lee, E. W. Magnetostriction and magnetomechanical effects. Rep. Prog. Phys. 18, 184-229 (1955).

31. Dionne, G. F. A review of ferrites for microwave applications. Proc. IEEE 63, 777-789 (1975). 
32. Schlömann, E. The microwave susceptibility of polycrystalline ferrites in strong DC fields and the influence of nonmagnetic inclusions on the microwave susceptibility. in Conference on Magnetism and Magnetic Materials, AIEE Spec. Publ. T-91, 600 (1956).

33. Dionne, G. F. Effect of porosity on the ferrimagnetic resonance linewidth. Mater. Res. Bull. 5, 939-946 (1970).

34. Kittel, C. On the theory of ferromagnetic resonance absorption. Phys. Rev. 73, 155-161 (1948).

35. Harward, I., Nie, Y., Gardner, A., Reisman, L. \& Celinski, Z. Al doped Ba hexaferrite $\left(\mathrm{BaAl}_{\mathrm{x}} \mathrm{Fe}_{12-\mathrm{x}} \mathrm{O}_{19}\right)$ thin films on Pt using metalloorganic decomposition. J. Appl. Phys. 111, 07A514 (2012).

36. Takeda, S., Kawai, T., Hotchi, T., Motomura, S. \& Suzuki, H. Buffler effects in the in-plane ferromagnetic resonance of a flat garnet. The 37th Annual Conference on Magnetics in Japan, 4pF-6 (2013). (in Japanese)

37. Emori, S. et al. Coexistence of low damping and strong magnetoelastic coupling in epitaxial spinel ferrite thin films. Adv. Mater. 29, 1701130 (2017).

38. Ren, Y. et al. Correlation between ultrafast demagnetization process and gilbert damping in amorphous TbFeCo films. IEEE Trans. Magn. 49, 3159 (2013).

39. Dionne, G. F. The magnetoelastic ion: friend and foe to microwaves. IEEE Trans. Magn. 47, 272-278 (2011).

40. Suzuki, Y. Epitaxial spinel ferrite thin films. Annu. Rev. Mater. Res. 31, 265-289 (2001).

41. Datta, R. et al. Formation of antiphase domains in $\mathrm{NiFe}_{2} \mathrm{O}_{4}$ thin films deposited on different substrates. Appl. Phys. Lett. 97, 071907 (2010).

42. Li, N. et al. Microstructural and ferromagnetic resonance properties of epitaxial nickel ferrite films grown by chemical vapor deposition. Appl. Phys. Lett. 101, 132409 (2012).

43. Heinrich, B. in Ultrathin magnetic structures III, (Eds. Bland, J. A. C. \& Heinrich, B.) 143-210 (Springer, Berlin, 2005).

44. Sparks, M. in Ferromagnetic-relaxation theory, (McGraw-Hill, New York, 1964).

45. Srivastava, A. K. et al. Angle dependence of the ferromagnetic resonance linewidth and two magnon losses in pulsed laser deposited films of yttrium iron garnet, MnZn ferrite, and NiZn ferrite. J. Appl. Phys. 85, 7838 (1999).

46. McMichael, R. D. \& Krivosik, P. Classical model of extrinsic ferromagnetic resonance linewidth in ultrathin films. IEEE Trans. Magn. 40, 2-11 (2004).

47. Mewes, C. K. A. \& Mewes, T. in Handbook of nanomagnetism: applications and tools, (Ed. Lukaszew, R. A.) 71-95 (Pan Stanford, 2015).

48. Roy, D. et al. Investigation on two magnon scattering process in pulsed laser deposited epitaxial nickel zinc ferrite thin film. $J$. Phys. D: Appl. Phys. 48, 125004 (2015).

49. Ade, R., Chen, Y. S. \& Lin, J. G. Effect of atomic replacement on the magnetic anisotropy in epitaxially grown ferrite thin films. J. Magn. Magn. Mater. 496, 165956 (2020).

50. Kondo, K. et al. Conducted noise suppression effect up to $3 \mathrm{GHz}$ by NiZn ferrite film plated at $90{ }^{\circ} \mathrm{C}$ directly onto printed circuit board. J. Appl. Phys. 93, 7130 (2003).

\title{
Acknowledgements
}

Y. Y. is indebted to Dr. S. Takeda for a fruitful discussion of the magnetic phenomena under high-frequency environments, and to Professor S. Yoshida for a preparation of composite material and measurements of loss properties. Short-circuited microstrip line measurements reported in this paper were carried out by Dr. S. Takeda at the KEYCOM Corporation, Tokyo, Japan. This work has been financially supported by Nippon Sheet Glass Foundation for Materials Science and Engineering. A part of this work was supported by NIMS microstructural characterization platform as a program of "Nanotechnology Platform" of the Ministry of Education, Culture, Sports, Science and Technology (MEXT), Japan, Grant Number JPMXP09A16NM0025.

\section{Author contributions}

Y.Y. planed the research project, prepared samples, and evaluated fundamental physical properties of the samples. S.Y. and K.N. performed microstrip line-probe measurements and analyzed data. M.K., J.L., and T.T. performed Mössbauer measurements. Y.Y. led the writing of the paper with a contribution from S.E.S.

\section{Competing interests}

The authors declare no competing interests.

\section{Additional information}

Correspondence and requests for materials should be addressed to Y.Y.

Reprints and permissions information is available at www.nature.com/reprints.

Publisher's note Springer Nature remains neutral with regard to jurisdictional claims in published maps and institutional affiliations.

\begin{abstract}
Open Access This article is licensed under a Creative Commons Attribution 4.0 International License, which permits use, sharing, adaptation, distribution and reproduction in any medium or format, as long as you give appropriate credit to the original author(s) and the source, provide a link to the Creative Commons licence, and indicate if changes were made. The images or other third party material in this article are included in the article's Creative Commons licence, unless indicated otherwise in a credit line to the material. If material is not included in the article's Creative Commons licence and your intended use is not permitted by statutory regulation or exceeds the permitted use, you will need to obtain permission directly from the copyright holder. To view a copy of this licence, visit http://creativecommons.org/licenses/by/4.0/.
\end{abstract}

(c) The Author(s) 2021 